\title{
HUBUNGAN JARAK KEHAMILAN DENGAN TEKANAN DARAH IBU HAMIL PREEKLAMPSIA
}

\author{
Diki Retno Yuliani, Puji Hastuti \\ Poltekkes Kemenkes Semarang \\ email: dikiretnoyuliani@gmail.com
}

\begin{abstract}
Inter-pregnancy interval is a risk factor for preeclampsia, and an increase in blood pressure is a sign of preeclampsia. The purpose of this study was to determine the relationship between inter-pregnancy interval and blood pressure. The study design was a cross sectional analytic survey research. The population was preeclampsia pregnant women in Banyumas District with cluster sampling technique. The results of the study were a relationship between inter-pregnancy interval with systolic blood pressure ( $p$ 0.017) and no relationship between inter-pregnancy interval with diastolic blood pressure ( $p$ 0.629). The conclusion of this study, there was a relationship between inter-pregnancy interval with systolic blood pressure in preeclampsia pregnant women.
\end{abstract}

\section{Keywords: inter-pregnancy interval; blood pressure; preeclampsia}

\begin{abstract}
ABSTRAK
Jarak kehamilan adalah salah satu faktor risiko preeklampsia, dan peningkatan tekanan darah adalah salah satu tanda preeklampsia. Tujuan studi ini untuk mengetahui hubungan jarak kehamilan dengan tekanan darah. Desain penelitian adalah penelitian survey analitik cross sectional. Populasi adalah ibu hamil preeklampsia di Kabupaten Banyumas dengan teknik cluster sampling. Hasil penelitian adalah Ada hubungan antara jarak kehamilan dengan tekanan darah sistolik ( 0,017$)$ dan tidak ada hubungan antara jarak kehamilan dengan tekanan darah diastolik ( $p$,629). Kesimpulan studi ini adalah ada hubungan jarak kehamilan dengan tekanan darah sistolik ibu hamil preeklampsia.
\end{abstract}

Kata Kunci: jarak kehamilan; tekanan darah; preeklampsia

\section{Pendahuluan}

Penyebab kematian ibu di Indonesia mayoritas adalah perdarahan, hipertensi dalam kehamilan (HDK) dan infeksi. Pada periode 2010 - 2013, HDK memiliki tren yang berbeda dari penyebab kematian dominan yang lain, yaitu untuk infeksi dan perdarahan cenderung mengalami penurunan, sedangkan HDK justru mengalami peningkatan dari tahun ke tahun (KEMENKES, 2015).

Preeklampsia adalah salah satu jenis hipertensi dalam kehamilan, yaitu penyakit hipertensi yang spesifik karena kehamilan disertai dengan gangguan pada multisistem dan timbul setelah usia kehamilan 20 minggu
(ACOG, 2013). Preeklampsia menjadi penyebab utama kematian ibu di Kabupaten Banyumas, dimana pada tahun 2018 (sampai bulan Juni) $54 \%$ kematian ibu disebabkan oleh PEB / eklampsia. Angka tersebut meningkat jika dibandingkan dengan tahun 2017, yaitu $50 \%$ kematian ibu disebabkan oleh PEB/ eklampsia (Banyumas, Juni 2018).

Penyebab pasti preeklampsia sampai saat ini masih belum diketahui, sehingga upaya pencegahan primer dengan menghidari atau mengontrol penyebab preeklampsia belum dapat dilaksanakan. Sedangkan faktor risiko preeklampsi meliputi usia > 40 tahun, nulipara, riwayat preeklampsia sebelumnya pada ibu hamil, 
ibu dan saudara kandung, jarak kehamilan > 10 tahun, kehamilan dengan pasangan baru, obesitas, diabetes mellitus, hipertensi kronik, kehamilan kembar, penyakit ginjal, kehamilan inseminasi dan sindrom antifosfolipid (Wibowo et al., 2016).

Jarak kehamilan adalah salah satu faktor risiko preeklampsia, sebuah studi melaporkan bahwa risiko preeklampsia pada ibu hamil dengan jarak kehamilan 10 tahun atau lebih adalah sama dengan nulipara. Studi lain melaporkan bahwa risiko preeklampsia akan semakin meningkan sesuai dengan bertambahnya jarak dengan kehamilan pertama. Banyak tanda-tanda dari preeklampsia, namun peningkatan tekanan darah sistolik dan diastolik merupakan tanda yang harus ada pada kondisi preeklampsia, baik pada preeklampsia saja ataupun preeklampsia dengan perburukan dan eklampsia (Wibowo et al., 2016). Oleh karena itu, studi ini bertujuan untuk mengetahui hubungan antara jarak kehamilan dengan tekanan darah pada ibu hamil preeklampsia.

\section{Metode Penelitian}

Desain penelitian yang digunakan adalah penelitian survey analitik cross sectional. Populasi penelitian ini adalah ibu dengan preeklampsia di Kabupaten Banyumas. Sampel sejumlah $15 \%$ dari populasi (populasi > 100) yaitu 32 ibu hamil dengan preeklampsia ringan dengan cluster sampling. Sampel adalah ibu yang pernah terdeteksi preeklampsia ringan, dalam pengawasan puskesmas dan telah mendapatkan terapi pencegahan sekunder preeklampsia seperti kalsium dosis tinggi dan aspirin dosis rendah.

Pengumpulan data melalui wawancara untuk mengisi kuesioner dan pengukuran tekanan darah. Tekanan darah diukur menggunakan tensimeter digital dan dilaksanakan sebanyak tiga kali, kemudian di ambil rata-ratanya dan setelah responden diberi kesempatan duduk tenang selama 15 menit. Analisis data menggunakan spearman rank. Ethical clerence diajukan pada komisi etik penelitian, Fakultas Kedokteran Universitas Jendral Soedirman, No Ref : 0917/KEPK/II/2019.
Tabel 1. Karakteristik Responden

\begin{tabular}{|c|c|c|}
\hline \multirow[t]{2}{*}{ Parameter } & \multicolumn{2}{|c|}{ frekuensi } \\
\hline & $\mathrm{N}$ & $\%$ \\
\hline \multicolumn{3}{|l|}{ Usia } \\
\hline$<20$ tahun & 1 & 3,1 \\
\hline 20-35 tahun & 12 & 37,5 \\
\hline$>35-40$ th & 13 & 40,6 \\
\hline$>40$ tahun & 6 & 18,8 \\
\hline Total & 32 & 100 \\
\hline \multicolumn{3}{|l|}{ Pendidikan } \\
\hline SD & 15 & 47 \\
\hline SMP & 9 & 28 \\
\hline SMA/SMK & 8 & 25 \\
\hline PT & 0 & 0 \\
\hline Total & 32 & 100 \\
\hline \multicolumn{3}{|l|}{ Pekerjaan } \\
\hline Karyawan & 1 & 3,1 \\
\hline Pedagang & 5 & 15,6 \\
\hline Buruh & 2 & 6,3 \\
\hline Ibu rumah tangga & 24 & 75 \\
\hline Total & 32 & 100 \\
\hline \multicolumn{3}{|l|}{ Paritas } \\
\hline Nulipara & 5 & 15,6 \\
\hline Primipara & 12 & 37,5 \\
\hline Multipara & 15 & 46,9 \\
\hline Grandemultipara & 0 & 0 \\
\hline Total & 32 & 100 \\
\hline \multicolumn{3}{|l|}{ Abortus } \\
\hline Tidak pernah & 28 & 87,5 \\
\hline 1 kali & 3 & 9,4 \\
\hline 2 kali & 0 & 0 \\
\hline 3 kali & 0 & 0 \\
\hline >3 kali & 1 & 3,1 \\
\hline Total & 32 & 100 \\
\hline \multicolumn{3}{|l|}{ Usia Kehamilan } \\
\hline Trimester II & 17 & 53,1 \\
\hline Trimester III & 15 & 46,9 \\
\hline Total & 32 & 100 \\
\hline
\end{tabular}

Karakteristik responden dapat dilihat pada tabel 1, yaitu mayoritas responden memiliki usia 35 - 40 tahun, paritas multipara, pekerjaan ibu rumah tangga, pendidikan SD, tidak ada riwayat abortus dan usia kehamilan trimester II.

Tabel 2. Distribusi frekuensi jarak kehamilan

\begin{tabular}{lcc}
\hline $\begin{array}{c}\text { Jarak } \\
\text { kehamilan }\end{array}$ & $\mathrm{N}$ & $\%$ \\
\hline Hamil & 5 & 15,6 \\
pertama & & \\
$<2$ tahun & 0 & 0 \\
$2-10$ tahun & 12 & 37,5 \\
$>10$ tahun & 15 & 46,9 \\
\hline Total & 32 & 100 \\
\hline
\end{tabular}

\section{Hasil dan Pembahasan}


Data jarak kehamilan responden dapat dilihat pada tabel 2, mayoritas responden memiliki jarak kehamilan > 10 tahun, dan terbanyak kedua adalah jarak kehamilan 2-10 tahun. Jarak kehamilan pada ibu hamil preeklampsia yang cenderung panjang sesuai dengan sebuah studi yang melaporkan bahwa ibu hamil multipara dengan preeklampsia rerata jarak kehamilaan adalah 7,3 tahun, sedangkan rerata jarak kehamilan multipara normal hanya 4,2 tahun (Harutyunyan, Armenian, \& Petrosyan, 2013). Namun hasil penelitian tidak sesuai dengan studi yang melaporkan bahwa jarak kehamilan terbanyak adalah 2-5 tahun baik pada preeklampsia ringan maupun preeklampsia berat, dan terbanyak kedua adalah jarak kehamilan > 5 tahun (Hutabarat, Suparman, \& Wagey, 2016).

Tabel 3. Distribusi frekuensi tekanan darah sistolik dan diastolik

\begin{tabular}{lcc}
\hline \multicolumn{1}{c}{ Tekanan darah } & $\mathrm{N}$ & $\%$ \\
\hline Sistolik (dalam mmHg) & & \\
\hline$<120$ & & \\
$120,01-140$ & & \\
$140,01-160$ & & \\
$>160$ & & \\
Total & 32 & 100 \\
\hline Diastolik (dalam mmHg) & & \\
\hline$<80$ & 5 & 15,6 \\
$80,01-90$ & 0 & 0 \\
$90,01-110$ & 12 & 37,5 \\
$>110$ & 15 & 46,9 \\
Total & 32 & 100 \\
\hline
\end{tabular}

Data tekanan darah responden dapat dilihat pada tabel 3 , yaitu mayoritas tekanan darah sistolik 120,01-140 $\mathrm{mmHg}$ dan tekanan darah diastolik 80,01-90 mmHg. Tekanan darah sistolik $<140 \mathrm{mmHg}$ dan diastolik < $90 \mathrm{mmHg}$ belum termasuk kategori preeklampsia, namun pada penelitian ini responden adalah ibu hamil preeklampsia yang berada dalam pengawasan puskesmas serta sudah mendapatkan terapi pencegahan sekunder preeklampsia seperti kalsium dosis tinggi dan aspirin dosis rendah, sehingga di anggap wajar jika tekanan darah saat ini cenderung masih stabil.

Tabel 4. Hasil uji korelasi spearman rank

\begin{tabular}{|c|c|c|c|c|c|}
\hline \multirow[t]{2}{*}{ Variabel } & \multicolumn{5}{|c|}{ Jarak kehamilan } \\
\hline & $\begin{array}{l}\text { Hamil } \\
\text { pertama }\end{array}$ & $<2$ th & $\begin{array}{c}2-10 \\
\text { th }\end{array}$ & $>10$ th & $\begin{array}{c}\mathrm{p}- \\
\text { value }\end{array}$ \\
\hline \multicolumn{6}{|c|}{ Tekanan darah sistolik (dalam $\mathrm{mmHg}$ ) } \\
\hline$<120$ & 4 & 0 & 3 & 3 & $0,017^{\star}$ \\
\hline $\begin{array}{l}120,01- \\
140\end{array}$ & 1 & 0 & 9 & 9 & \\
\hline $\begin{array}{l}140,01- \\
160\end{array}$ & 0 & 0 & 0 & 3 & \\
\hline$>160$ & 0 & 0 & 0 & 0 & \\
\hline Total & 5 & 0 & 12 & 15 & \\
\hline \multicolumn{6}{|c|}{ Tekanan darah diastolik (dalam $\mathrm{mmHg}$ ) } \\
\hline$<80$ & 2 & 0 & 2 & 4 & 0,629 \\
\hline $\begin{array}{l}80,01- \\
90\end{array}$ & 3 & 0 & 6 & 7 & \\
\hline $\begin{array}{l}90,01- \\
110\end{array}$ & 0 & 0 & 4 & 4 & \\
\hline$>110$ & 0 & 0 & 0 & 0 & \\
\hline Total & 5 & 0 & 12 & 15 & \\
\hline
\end{tabular}

Hasil uji korelasi spearman rank dapat dilihat pada tabel 4 , diperoleh $p$ value 0,017 untuk korelasi antara jarak kehamilan dengan tekanan darah sistolik dan $p$ value 0,629 untuk korelasi antara jarak kehamilan dengan tekanan darah diastolik. Dapat disimpulkan bahwa ada hubungan antara jarak kehamilan dengan tekanan darah sistolik, namun tidak ada hubungan antara jarak kehamilan dengan tekanan darah diastolik. Hal tersebut sesuai dengan studi yang melaporkan bahwa ada hubungan antara jarak kehamilan dengan kejadian preeklampsia pada ibu hamil (Widiastuti, 2019).

Sebuah studi meta analisis melaporkan bahwa jika dibandingkan dengan jarak kehamilan 2-4 tahun, jarak kehamilan yang lebih pendek $(<2$ tahun) tidak berhubungan dengan peningkatan risiko preeklampsia berulang, tetapi jarak kehamilan yang lebih lama (> 4 tahun) tampaknya meningkatkan risiko preeklampsia (Cormick, Betran, Ciapponi, Hall, \& Hofmeyr, 2016). Hasil penelitian ini sesuai dengan studi meta analisis tersebut, dimana responden ibu dengan preeklampsia, tercatat tidak ada yang memiliki jarak kehamilan $<2$ tahun, sedangkan jarak kehamilan > 10 merupakan jarak kehamilan mayoritas.

Sebuah studi melaporkan bahwa ibu hamil multigravida dengan jarak kehamilan lebih dari 5 tahun mempunyai risiko 4,49 kali menderita preeklampsia dibandingkan 
dengan ibu multigravida dengan jarak kehamilan 1-3 tahun (KHAIRUNNISA, 2018). Studi lain melaporkan ibu dengan jarak kehamilan > 5 tahun mempunyai risiko 2,802 kali menderita preeklampsia dibandingkan ibu hamil dengan jarak kehamilan 2-5 tahun (Kartikadewi, Theresia, \& Meila, 2017). Ada pula yang melaporkan risiko preeklampsia meningkat 1,39 kali pada jarak kehamilan 3 tahun dan risiko preeklampsia meningkat 2,05 kali pada jarak kehamilan 4 tahun (Hercus, Dekker, \& Leemaqz, 2018).

Jarak kehamilan yang semakin panjang yang menjadi faktor risiko preeklampsia, menunjukkan bahwa efek perlindungan dari kehamilan sebelumnya mungkin menurun seiring dengan waktu atau ada faktor-faktor tergantung waktu lain yang berkontribusi terhadap peningkatan risiko preeklampsia (Harutyunyan et al., 2013). Salah satu faktor tergantung waktu kemungkinan adalah usia. Usia > 40 tahun juga menjadi faktor risiko preeklampsia, yang dikaitkan dengan perubahan pembuluh darah endotel yang mengikuti bertambahnya usia ibu (Jahromi \& Husseini, 2008).

Usia secara umum juga menjadi faktor yang mempengaruhi tekanan darah, seiring bertambahnya usia, kejadian hipertensi akan semakain meningkat. Semakin bertambah usia, elastisitas pada dinding aorta semakin menurun, katup jantung menebal serta menjadi kaku, sehingga kemampuan jantung untuk memompa darah juga menurun. Selain itu pembuluh darah juga kehilangan elastisitasnya sehingga meningkatkan resistensi pembuluh darah perifer, yang kemudian akan meningkatkan tekanan darah (Aspiani, 2016).

Pada hipertensi dalam kehamilan, salah satunya preeklampsia terjadi permasalahan dalam invasi sel trofoblas pada lapisan otot arteri spiralis dan jaringan di sekitarnya, sehingga lumen arteri spiralis tidak mengalami distensi dan vasodilatasi. Akibatnya arteri spiralis relatif vasokontriksi (diameter 200 mikron) dan terjadi kegagalan "remodeling arteri spiralis" sehingga aliran darah uteroplasenta menurun dan menyebabkan hipoksia dan iskemia plasenta. Dampak iskemia tersebut akan menimbulkan perubahan-perubahan yang dapat menjelaskan patogenesis preeklampsia selanjutnya (Saifuddin, Rachimhadhi, \& Wiknjosastro, 2014).

Banyak studi terkait hubungan jarak kehamilan dengan preeklampsia, namun belum diketahui dengan pasti rentang berapa jarak kehamilan bisa menjadi faktor risiko preeklampsia (Harutyunyan et al., 2013). Sebuah studi melaporkan bahwa jarak kehamilan yang lama dan primipaternitas menjadi faktor risiko independen preeklampsia pada multipara (Hercus et al., 2018). Studi lain melaporkan bahwa jarak kehamilan yang panjang tampaknya menjadi faktor risiko yang kuat untuk berkembangnya preeklampsia hanya pada wanita tanpa riwayat preeklampsia sebelumnya. Pada wanita multipara tanpa riwayat preeklampsia, risiko preeklampsia kemungkinan meningkat pada kehamilan berikutnya sejalan dengan meningkatnya jarak kehamilan. Sedangkan pada wanita multipara dengan riwayat preeklampsia, risiko preeklampsia cenderung berkurang sejalan meningkatnya jarak kehamilan. Hasil penelitian tersebut juga melaporkan bahwa risiko preeklapsia turun tajam setelah kelahiran anak pertama, namun risikonya meningkat seiring waktu. (Harutyunyan et al., 2013).

\section{Kesimpulan}

Kesimpulan dari studi ini adalah ada hubungan antara jarak kehamilan dengan tekanan sistolik, namun tidak ada hubungan antara jarak kehamilan dengan tekanan darah diastolik. Perlu dilakukan studi lebih lanjut dengan mengontrol variabel confounding dan jumlah sempel yang lebih besar.

\section{Ucapan Terima Kasih}

Ucapan terima kasih kami sampaikan kepada Kepala Dinas Kesehatan Kabupaten Banyumas Dan jajarannya yang telah memberikan ijin dalam pelaksanaan penelitian. 


\section{Daftar Pustaka}

ACOG. (2013). Hypertention in Pregnancy. Paper presented at the Task Force on Hypertention in Pregnancy, Washinton DC.

Aspiani, R. Y. (2016). Buku Ajar Asuhan Keperawatan Klien Gangguan Kardiovaskular Aplikasi NIC \& NOC. Jakarta: EGC.

Banyumas, D. K. K. (Juni 2018). Laporan Kesehatan Ibu, Anak Dan Gizi Masyarakat Kabupaten Banyumas. Banyumas: Seksi Kesga Dan Gizi Bidang Kesehatan Masyarakat Dinas Kesehatan Kabupaten Banyumas.

Cormick, G., Betran, A. P., Ciapponi, A., Hall, D. R., \& Hofmeyr, G. J. (2016). Inter-pregnancy interval and risk of recurrent pre-eclampsia: systematic review and meta-analysis. Reproductive health, 13(1), 83.

Harutyunyan, A., Armenian, H., \& Petrosyan, V. (2013). Interbirth interval and history of previous preeclampsia: a case-control study among multiparous women. BMC Pregnancy and Childbirth, 13(1), 244.

Hercus, A., Dekker, G., \& Leemaqz, S. (2018). Primipaternity and birth interval; independent risk factors for preeclampsia. The Journal of Maternal-Fetal \& Neonatal Medicine, 1-4.

Hutabarat, R. A., Suparman, E., \& Wagey, F. (2016). Karakteristik pasien dengan preeklampsia di RSUP Prof. Dr. RD Kandou Manado. e-CliniC, 4(1).

Jahromi, B. N., \& Husseini, Z. (2008). Pregnancy Outcome at Maternal Age 40 and Older. Taiwanese Journal of Obstetrics and Gynecology, 47(3), 318-321. doi: https://doi.org/10.1016/S1028-4559(0 8)60131-X

Kartikadewi, R., Theresia, E. M., \& Meila, N. (2017). Rasio Prevalensi Jarak Kehamilan Terhadap Kejadian Preeklampsia Pada Ibu Bersalin Di RSUD Sleman Tahun 2016.
Poltekkes Kemenkes Yogyakarta.

KEMENKES. (2015). Profil Kesehatan Indonesia Tahun 2014. Jakarta: Kementerian Kesehatan Republik Indonesia.

KHAIRUNNISA, F. (2018). Hubungan antara Jarak Waktu Kehamilan dengan Kejadian Preeklampsia pada Ibu Hamil Multigravida di RSUD Moewardi Surakarta. ( Skripsi), Universitas Sebelas Maret.

Saifuddin, A. B., Rachimhadhi, T., \& Wiknjosastro, G. H. (2014). Ilmu Kebidanan Sarwono Prawirohardjo. Jakarta: PT Bina Pustaka Sarwono Prawirohardjo.

Wibowo, N., Irwinda, R., Frisdiantiny, E., Karkata, M. K., Johannes C Mose, Maisuri T Chalid, . . . Manggala Pasca Wardhana. (2016). Pedoman Nasional Pelayanan Kedokteran Diagnosis Dan Tata Laksana Pre-Eklamsia. Jakarta: POGI.

Widiastuti, Y. P. (2019). Indeks Massa Tubuh (IMT), Jarak Kehamilan dan Riwayat Hipertensi Mempengaruhi Kejadian Preeklampsia. Jurnal Ilmu Keperawatan Maternitas, 2(2), 6-22. 